\title{
Safe and healthy integration into semiskilled jobs: does gender matter?
}

\author{
Marie Laberge ${ }^{\mathrm{a},{ }^{*}}$, Nicole Vézina ${ }^{\mathrm{a}}$ and Johanne Saint-Charles ${ }^{\mathrm{a}}$ \\ ${ }^{a}$ CINBIOSE, Université du Québec à Montréal, case postale 8888, succursale Centre-ville \\ Montréal (Québec) H3C 3P8 Canada
}

\begin{abstract}
Women report fewer injuries than men when they are young, but report a higher proportion of professional diseases later in life $(35$ years +$)$. Understanding early work conditions that lead to postponed health outcomes is necessary if we are to prevent women's injury as well as men's. Introduction to work and safe integration programs are often put forward to prevent injuries among youth. This paper aims to illustrate some differences in the job introduction / integration process for men and women and to discuss some gender-based Occupational Health and Safety (OHS) implications. Data come from two waves of interviews with 31 students enrolled in vocational training for a semiskilled trade. Results demonstrated differences between men and women: trades chosen, OHS complaints, supervising patterns, integration to work, etc. Women often choose customer service jobs, have less formal supervision and are often left to themselves when learning to do their job. Men declared more accidents while women reported more musculoskeletal symptoms. Findings from this research suggest young women's OHS issues should not be trivialized and that specific youth prevention programs for sectors where women are more present, such as customer service, should be developed.
\end{abstract}

Keywords: Gender differences, young workers, ergonomic approach, work socialization, occupational health and safety

\section{Introduction}

Young workers are more frequently injured at work than their older colleagues [3, 17]. Some young workers are at higher risk than their peers, including adolescents between the age of 15 and 19 who no longer attend school $[5,13]$. The higher risk levels of these young people may be related to the kind of jobs they hold (e.g. manual jobs, physically demanding jobs, less social support) [2, 5-6, 13].

\subsection{Gender considerations}

The full-time equivalent (FTE) injury rate of young workers between 15 and 24 years old (5.8\%) is two and a half times higher for men $(7.9 \%)$ than for women $(3.2 \%)$ [12]. While the injury rate of men seems to decrease with age, the trend appears to be inversed for women [30]. Occupational Health and Safety (OHS) data reveal that the majority of young workers' injuries is related to work accidents (99\% of injuries vs. $96 \%$ for workers over 25 years old) which are sudden and unforeseen events, attributable to any cause, arising out of or in the course of work $[10,25]$. Occupational diseases account for less than $1 \%$ of young workers' occupational injuries while accounting for $4 \%$ of older workers' injuries. The proportion of occupational diseases among all occupational injuries is higher for women than for men (5.5\% vs. $1.9 \%$ for men in Quebec in 2000) [26]. These occupational diseases are mostly work-related musculoskeletal disorders (WMSD) (59\% of diseases are WMSD for women and 53\% for men) [26]. Since occupational diseases develop gradually over time, young women report fewer injuries when they are young, possibly owing to the risk factors they are exposed to that lead to delayed health conditions. Assessment of early risk factors that lead to postponed health conditions may, therefore, help better understand some of the gendered differences in injury scenarios.

\footnotetext{
${ }^{*}$ Corresponding author. E-mail: laberge.marie@sympatico.ca.
} 
According to Breslin [4], young men and women seem to share a common vision of OHS. Both tend to trivialize the importance of OHS, arguing that minor injuries are normal and are simply "part of the job". Both hesitate to talk about OHS or to declare a minor injury in their respective workplace. While young women are worried about being perceived negatively by their supervisor (vertical relationships), young men are afraid to be considered immature by their coworkers (horizontal relationships). These results illustrate the importance of considering the social component of work activity in order to fully understand the work skills learning process, including health protection.

\subsection{Workplace integration and $O H S$}

To prevent young worker's injury, organizations are increasingly establishing introduction and safe integration programs [11]. Existing tools developed to support these programs often propose planning the first few days of work: welcome the newcomer, explain politics and OHS rules, organize and provide a training session and designate a companion in charge of on-the-job training [19]. However, the integration process into semiskilled trades involves many other people and takes more than a few days - as suggested by these support tools [19]. Studies have also shown that OHS learning is never dissociated from job-skills learning $[9,23]$. Thus, training sessions that take place away from the job are often inefficient or inappropriate [27].

The introduction and integration period is crucial to developing knowledge and efficient know-how that protect health and safety. Several studies suggest that this period of time should involve the participation of experienced workers and should occur under work conditions that provide a "margin of manoeuvre" for both trainers and trainees [8-9, 14, 23-24, 29]. It is therefore relevant to understand the real integration process into a new job before prescribing how to integrate OHS issues. And, since there are differences in OHS patterns between men and women, it is imperative to document this process using a gendersensitive approach.

\subsection{The study context}

In Quebec (Canada), while the Commission de la santé et de la sécurité du travail (CSST) - the organization entrusted with administering the occupational health and safety (OHS) plan - is developing a strong prevention program targeting young workers, the Ministry of Education (MELS) has just implemented an important reform of the educational system.

This reform led to the creation of a new cooperative training program for adolescents with mild to moderate learning difficulties and at risk of dropping out: the Training for a Semiskilled Trade (TST) program [21]. This program takes place over one school year and offers minimum qualification for employment in various trades. During the year, students spend part of their week at school and the other part at work. Candidates for the TST program need to have completed primary school and currently be experiencing some difficulty in finishing their first cycle of secondary school (Grades 7-8).

Each student has to choose a specific semiskilled job from a list of more than 100 trades and complete an internship of 375 hours within an organisation chosen jointly by the student and their teacher. The process of learning work skills is done at the workplace. At school, students pursue their general education, which includes a class to prepare them for the job market (e.g. how to make a CV, labour code).

The TST program has been running since 2007 and data shows that almost two thirds of the cohort is male. Jobs offered by the TST Directory are those most often done my men (e.g. Tire Installer) [16].

In 2008-2010, the Quebec Ministry of Education funded an action-research project aiming to prevent occupational injuries among students enrolled in the new TST program. This project sought to better understand the real-life process of introduction and integration into work for young TST trainees so as to improve the TST program and to ensure that OHS is embedded in the job-skills development process. One way to do this is to describe the gap between the reallife process and the written program (the prescription) and to find a way to reconcile this gap. This paper focuses on the gender issues revealed by this action-research project. The objectives are 1) to illustrate some differences in the job introduction and integration process for young men and women and 2) to discuss some gender-based implications about OHS training and prevention.

\section{Methodology}

The methodological framework has been inspired by the work activity analysis approach developed by ergonomists $[15,28]$, which aims at improving work situations. The first ergonomic intervention target 
was the TST program, specifically to understand the program implementation by analysing work situations experienced by young trainees.

The ergonomic intervention took place in two distinct schools, each in a different socio-economic area (urban and suburban). Together, these schools admit 90 students into the TST program (73\% male). Of these, 13 women and 18 men were selected to participate in the study after ensuring their free and informed consent. As the ergonomic work activity analysis suggested [15], before proposing modifications to the TST program, it is necessary to better understand and document the situation. To do so, multiple sources of data were used: questionnaires and interviews were conducted with the key informants (students, teachers, workplace supervisors and co-workers) and observations of the work activities were made.

For this paper, the main data source is individual semi-structured interviews with 31 students at two moments in their internship, T1 $(n=31$ students met after a mean of 1.7 weeks after the first day of their internship) and T2 ( $\mathrm{n}=26$ students met after a mean of 6.7 months of their internship). Similar topics were covered in interviews conducted at T1 and T2 with the necessary adjustments to take into account the passing of time. A first topic was related to work conditions, health outcomes, previous injuries and musculoskeletal symptoms. Other topics were professional aspirations, OHS representations, workplace representations, introduction and integration experience, satisfaction and difficulties encountered. In the first interview, students were also asked to describe their internship and to share their expectations. The following was addressed only in the last interview: concordance between expectations and real experience, operative resources built along the apprenticeship process (as described by Chatigny) [9], relationships developed with co-workers and supervisors. Since there were both closed and open-ended questions, transcripts were put into an Excel sheet. Closed questions were analyzed quantitatively, mainly by frequency and means. Open-ended questions were analyzed qualitatively with a content analysis methodology using categorization to identify some typologies of answers according to the topic. The answers of men and women were then compared.

\section{Results}

Among jobs offered in the Semi-skilled Trades Directory (MELS), women and men have not chosen the same ones (Table 1). The only job chosen by both men and women is Stock Handler in a Retail Store. This is the most popular job, both for young men and women; however, the kind of retail store differs according to gender. Young women chose retail clothing stores and cosmetic departments in pharmacies, while men chose stores where the goods are mainly bulkier and heavier: hardware (2), appliances and electronics (1), office furniture (1) and pharmacies (merchandising department) (2).

Table 1

Jobs chosen by women and men

\begin{tabular}{|c|c|}
\hline $\mathrm{F}(\mathrm{n}=13)$ & $M(n=18)$ \\
\hline $\begin{array}{l}\text { - Stock Handler i } \\
\text { - Hair Salon Assistant (4) } \\
\text { - Office Clerk (2) } \\
\text { - Recreational centre atten- } \\
\text { dant (2) } \\
\text { - Groomer Assistant (1) }\end{array}$ & $\begin{array}{l}\text { Retail Store }(4 \mathrm{~F}-5 \mathrm{M}) \\
\text { - Tire installer (4) } \\
\text { - Wood Production Worker (2) } \\
\text { - Cook's Helper (2) } \\
\text { - } \text { Auto Parts Rental Clerk (2) } \\
\text { - Copy\& Print Centre Clerk (1) } \\
\text { - Butcher's Helper (1) } \\
\text { - Welder Assistant (1) }\end{array}$ \\
\hline
\end{tabular}

\subsection{Concordance between career aspirations and chosen trade}

After only a few days of internship, almost half of the female apprentices reported that the chosen job did not correspond to their career expectations (6/13), either because the job they wanted was not proposed in the Semiskilled Trades Directory (e.g. aesthetics, massage) or because the first days did not correspond to what they had imagined. On the other hand, a large majority of male apprentices reported a desire to do the same job later $(15 / 18)$, illustrating satisfaction with their choice and a good first impression.

The same question, asked at the end of the internship, revealed that three women and five men had changed their minds, nearly all adversely (they would not do the same job later). Only one woman changed her mind positively, coming to the conclusion that her job could be of interest to her later, contrary to what she had first thought.

\subsection{OHS apprehension and health outcomes reported}

A majority of the women interviewed doubt that they could get injured at work (10/13 at T1 and 8/11 at T2). Among the minority who do consider the pos- 
sibility of being injured, reported either at $\mathrm{T} 1$ or $\mathrm{T} 2$, two female stock handlers identified risks of falling from heights, cuts using knives and the possibility of being hit by falling objects; a Hair Salon Assistant identified some tool hazards (cuts and burns with scissors and irons); and finally, a Recreational centre Attendant in a public pool pointed out some sliding hazards and the possibility of being injured while lifting heavy loads.

More young men considered that they could be injured at work (9/18 at $\mathrm{T} 1$ and 9/15 at T2). Hazards identified including those related to machines, physical effort (manual handling and effort with tools), tools (cuts, burns) and the possibility of being hit by a falling or moving object.

Among the whole group, 19 apprentices reported at least one injury episode during their TST internship. Out of these 19, 14 are young men. The reported injuries were mostly minor incidents (small cuts or burns for example).

Women and men differ with regard to their workrelated musculoskeletal symptoms. At the end of the internship, young trainees were asked to identify work-related musculoskeletal symptoms in different parts of their body. Lower back pain/symptoms are the most important for both men and women, with a higher rate for women; up to $73 \%$ of young women reported lower back symptoms vs. $40 \%$ for men. Foot-related symptoms also differed across genders (women: $61.5 \%$ vs. men: $22.5 \%$ ), as well as upper limb symptoms. While more women identified symptoms in both hands (right hand, women: $38.5 \%$ vs. men: $20 \%$; left hand, women: $30.8 \%$ vs. men: $13.3 \%$ ), more men identified symptoms in both shoulders (right shoulder; women: $30.8 \%$ vs. men: $40 \%$; left shoulder; women: $23.1 \%$ vs. men: $33.3 \%$ ). Men seem to report more symptoms in the proximal body regions (e.g. thighs, shoulders) while women report proportionally more symptoms in the distal body parts (e.g. hands and feet).

\subsection{Introduction to the workplace - the experience after few days (T1)}

Early in their internship, students described their first day at work: What were they first asked to do? How were they welcomed by their supervisor and coworkers? No one reported being formally oriented by a Human Resources Service in their organisation. However, they all described having received tacit and/or on-the-job training by some co-workers not always formally enrolled to this end. The experiences reported are very diverse; some apprentices considered that they were well introduced while others expressed some disappointment. Although the experiences were all different, there are still notable differences between the experiences of men and women. Overall, more women than men expressed some disappointment regarding the first days at work.

Q1: "The owner of the Hair Salon was on Holiday

for two weeks. I was welcomed by Ana, the only

Hair Dresser there that day. [...]. She didn't know what to ask me to do, she then asked me to do some cleaning, such as removing products, cleaning shelves,... She was so busy at the time, so she didn't show me how to do it. I didn't put the products in their place properly. [...]. Later, she showed me and I put all the products in their proper place. I also swept the floor. A few times, I went to see her working, even if she did not necessarily ask me to do so. [...]. It was not a good first day. The next day, I didn't want to go back. She was mean to me. I was tired and nervous, I woke up at night, I couldn't sleep... I told myself I didn't want to return $»^{1}$. (a young Hair Salon Assistant)

While the program specifications mentioned that every apprentice should be formally accompanied by a specific supervisor, many apprentices, both women and men, experienced more informal supervision. However, more male apprentices described a wellorganized introduction to work and a richer social environment at the beginning of their internship.

Q2: "The first day, Peter, the boss, was expecting me. He introduced me to all the others, about 10-12 people. He showed me the place and explained to me how things work. Afterwards, I started changing my first 2-3 tires with Bob. He showed me and then, he asked me to do it... ». (A young Tire Installer)

When they described their first day, five women reported that the first person they met was not the expected one, while no men reported this situation. For these women, the introduction was sometimes planned (the formal supervisor had already asked another person to welcome her) or not; people in the workplace had to improvise on the spot.

Q3. " the first day, I met John, the owner, he didn't know that I was there for an internship; he asked me which hairdressing school I came from and he looked surprised to hear that I didn't come from a professional school but from the TST program [not specialized in hairdressing] " (another Hair Salon Assistant).

Students were asked to estimate how much time they spent with the person who showed them their first tasks on the first day (table 2). Results show that

\footnotetext{
${ }^{1}$ All the quotations are translated from French
} 
women were more often left to themselves during their first day when compared to men.

Table 2

Time spent with the person who had shown work tasks the first day at work

\begin{tabular}{lcc}
\hline & $\begin{array}{c}\mathrm{F} \\
(\mathrm{N}=13)\end{array}$ & $\begin{array}{c}\mathrm{M} \\
(\mathrm{N}=18)\end{array}$ \\
\hline Less than one hour or on down time only & 6 & 2 \\
Between one hour and a half day & 4 & 0 \\
The whole day & 3 & 16 \\
\hline
\end{tabular}

This last finding illustrates different job contents in the early stages of the internship for male and female teenagers. In general, young women began by undertaking tasks only distantly related to their training rather than the core tasks they were supposed to learn (8/13 women) These secondary tasks required less supervision (e.g. cleaning, document filing). In contrast, almost all male apprentices performed their main tasks immediately on their first day $(15 / 18$ men) and were accompanied by a co-worker or a supervisor (e.g. installing tire, stocking products, sanding wood, painting, preparing food).

\subsection{Workplace integration - the experience after a few months (T2)}

From a non-gendered perspective, a majority of apprentices reported a positive internship experience (20/26 students), but this portrait varies notably between men and women, given that almost half of the women were dissatisfied (5/11) while this was the case for only one man. Female apprentices who expressed more disappointment about their workplace integration were those who chose the Hair Salon Assistant job. They expected to do more client service and more personal care. Instead, they were asked to clean and tidy, including chores such as collecting hair, washing dye pots or storing hair products.

Students described a typical day at work both early in their internship as well as at the end. As previously mentioned, many female apprentices began their internship with secondary tasks, but this changed over time and the tasks accomplished became increasingly varied and significant (sales, cashier, marketing, office work, etc.). For men, jobs appear to have remained similar from beginning to end. They began to do their main tasks early in their internship and described doing the same work at the end. The process of integrating female workers seems to take longer.

Young trainees were asked towards the end of their internship which job tasks they would have wanted to learn. Young women expressed wanting to learn more in relation to dealing with clients, operating a cash register, and, for the young Hair Salon Assistants, doing more specialized tasks (like shampooing or color). One female apprentice's response to this question seems to indicate a potential lack of trust towards the TST apprentices.

Q4: "I learned everything except the cash register, but in the end, I don't want to learn it because I'm afraid of being accused of theft». (A stock handler in a clothing store)

Several male students expressed wanting to learn to operate machinery (vehicles, lift trucks, saws, cutters, electronic wrappers) and to partake in more specialized tasks (especially for the Tire Installers; they would have liked to learn other auto repair tasks). The two assistant cooks would have liked to learn more recipes and cooking techniques (e.g. dressing meat).

Students identified the different people involved in their training during the internship (Table 3). Overall, the results show that men mostly work with men and women mostly work with women. Also, the social network of men at work seems to be quantitatively more important than for women, i.e. they identified more colleagues involved in their training.

Table 3

Workers involved in training (number $\&$ gender) for men and women

\begin{tabular}{rcc}
\hline & $\mathrm{F}(\mathrm{N}=11)$ & $\mathrm{M}(\mathrm{N}=15)$ \\
\hline Total, apprentices identified & $\begin{array}{c}25 \mathrm{~F} \\
7 \mathrm{M}\end{array}$ & $\begin{array}{c}52 \mathrm{M} \\
5 \mathrm{~F}\end{array}$ \\
$\begin{array}{c}\text { Average number of people } \\
\text { identified /apprentice }\end{array}$ & 2.9 & 3.8 \\
$\begin{array}{r}\text { Number of co-workers identi- } \\
\text { fied/apprentice }\end{array}$ & $\begin{array}{c}\text { 4F identified } \\
\text { up to 4 } \\
\text { workers }\end{array}$ & $\begin{array}{c}\text { 6M identified } \\
\text { more than 5 } \\
\text { workers }\end{array}$ \\
\hline
\end{tabular}

\subsection{Knowledge transmission from experienced workers}

Students were asked to report how often their colleagues explained 1) What to do (tasks), 2) How to do (procedures), 3) Why to do (process), 4) Injury risks and how to prevent them, 5) Strategies for working faster and 6) Strategies that make it easier to do the job (Table 4). This transmission of knowledge seems to manifest itself differently according to gender. Female apprentices reported being told what to do, yet they often not receive explanation of how to 
do the task or why performing tasks in a particular way is important. As for men, they expressed that their peers had clearly explained what to do and how to do it. They also reported having had access to the "whys" more than women, even if this kind of knowledge is not the most important one for them. Overall, young men received information more often than young women for all knowledge types. Finally, OHS is not a subject that is frequently on the agenda, and this is particularly true for young women.

Table 4

Kind of information discussed with co-workers in the internship

\begin{tabular}{|c|c|c|c|c|}
\hline & \multicolumn{2}{|c|}{$\mathrm{F}(\mathrm{N}=11)$} & \multicolumn{2}{|c|}{$\mathrm{M}(\mathrm{N}=15)$} \\
\hline & $\begin{array}{c}\text { Very or } \\
\text { quite } \\
\text { often }\end{array}$ & $\begin{array}{l}\text { Rare / } \\
\text { Never }\end{array}$ & $\begin{array}{c}\text { Very or } \\
\text { quite } \\
\text { often } \mathrm{t}\end{array}$ & $\begin{array}{l}\text { Rare / } \\
\text { Never }\end{array}$ \\
\hline 1. What doing & 6 & 5 & 13 & 2 \\
\hline 2. How doing & 4 & 7 & 13 & 2 \\
\hline 3. Why doing & 2 & 9 & 8 & 7 \\
\hline 4. OHS hazards & 1 & 10 & 5 & 10 \\
\hline $\begin{array}{l}\text { 5. Strategies for } \\
\text { being faster }\end{array}$ & 0 & 11 & 6 & 9 \\
\hline $\begin{array}{l}\text { 6. Strategies for } \\
\text { making it easier }\end{array}$ & 2 & 9 & 4 & 11 \\
\hline
\end{tabular}

\section{Discussion}

Young worker's OHS is an important public health issue in Canada and elsewhere. The scientific literature and descriptive statistics focus largely on young men's injury rate. To reduce the injury rate of young workers, prevention institutions emphasise the importance of setting up good programs of introduction and safe integration into the workplace. Although such programs are not only targeted towards young men, they tend to develop more quickly in traditionally male-dominated trades [19]. The discussion underscores findings that are important to consider when elaborating safe and healthy job integration programs in sectors or occupations in which young women also participate.

\subsection{Occupational segregation and health outcomes}

TST students experience the gendered division of labour early in their careers. Other studies have demonstrated that men and women do not usually hold the same jobs and if so, they do not perform the same tasks [7, 22]. In this study, young men mainly chose jobs traditionally held by men and they mostly work with men. The same applied to women, showing a fairly strong gendered division of labor in the jobs chosen by students.

Accordingly, findings on occupational health outcomes are not surprising. In this study, young men reported more occupational accidents while young women reported more work-related musculoskeletal symptoms, in particular in the lumbar region and in the distal parts of the body (feet and hands). Although the sample size is relatively small, these results are consistent with large epidemiological and statistical studies [1, 26]. Our study indicates that young women do not have many work-related accidents (which is already known) but that their working conditions may lead to WMSD later in life. As a large majority of studies are primarily based on cross-sectional data (databases or cross-sectional surveys), they rarely address early exposures to injury that occur later in their life [17]. Because of the nature of young women's job risk factors, exposures are often underestimated. This is important to consider because exposures can lead to costly diseases for the individual and society (e.g. WMSD).

\subsection{Different introduction contexts for men and women}

As previously shown, early in the internship, several female students reported not wanting to perform the chosen job in the future. As demonstrated by Laberge et al. [16], the TST program offers a choice of jobs that tends to attract more young men, even when considering the male to female ratio in the program (one-third of TST students are women and 15\% of jobs in the Directory of Semiskilled Jobs tend to attract more women). Almost half of the men and half of the women interviewed said that the job they had as a trainee did not meet their future aspirations. Women voiced this early in the internship, while men expressed notably more dissatisfaction at the end of their training. Not projecting him-herself into a job can probably influence learning processes (OHS skills and knowledge in particular), especially when this feeling is present from the first days of training.

Otherwise, the study findings indicate several differences in the way men and women were welcomed to their workplace. Women were often left to themselves the first few days at work. The circumstances of customer service jobs can partly explain why coworkers are not always available even when a new worker arrives. This means that young female apprentices must often learn the job on their own. They therefore miss the situated learning that takes place in 
relationships [20]. Being left alone and doing less meaningful tasks, they lack access to the implicit job know-how and advice from co-workers that could help them protect themselves (e.g. strategies to reduce physical constraints) and prevent MS symptoms. Breslin et al. [4] showed that young women felt uncomfortable disrupting a supervisor to talk about OHS - the absence of a formal introduction into the workplace might explain in part this discomfort.

\subsection{Knowledge transmission from co-workers}

The young men in our study clearly had higher levels of meaningful contact with their co-workers, increasing the possibility of benefiting from various human resources in the learning process at work [9]. This was supported by our results showing that the nature and the quantity of knowledge transmitted appear to be different for men and women. This difference is more pronounced for knowledge regarding process (the whys). Almost all women say that they had rarely or never been told why they are asked to perform a task. This kind of knowledge appears to be important in building a repertory of "efficient knowhow" [23]. You can develop better strategies if you know why doing something in a certain way is important. This know-how allows workers to meet production requirements while keeping themselves in good health $[24,29]$.

None of the female students reported having been advised about OSH often or very often during their internship. This could contribute to their perception of not being at risk. These findings reinforce that women are often left to themselves in their learning.

\subsection{Limitations}

This study pointed out some gendered differences related to introduction and integration into a semiskilled job. While the information collected cannot be generalized to the entire TST population, this study has provided additional insight into different job integration experiences. Confirming some of these results with a larger sample would be beneficial. For example, women in the service sector often being left to themselves to learn a new job.

Also, individual results are linked to multiple workplace contexts. In this paper, different contexts were not described in detail. A better description of each context could also contribute to a better understanding of the learning and socializing processes and health outcomes in particular situations. Such a de- scription has been done, but not from a gendered perspective [18]. In fact, other workplace data were collected (video data, interviews with co-workers, etc.); however the companies that accepted female apprentices did not accept to participate in this part of the study. They argued that data collection would bother their customers (in particular the presence of a camera). A more appropriate methodological approach for the customer services context should be developed. Finally, a better understanding of gendered "organizational culture" that may develop in different occupations would be worthwhile.

\section{Conclusion}

Prevention programs for youth are mostly based on work injury statistics, so it is natural that emphasis be placed on men's OHS more than women's. Findings from this study suggest that prevention program developers should avoid trivializing young women OHS issues. In this study, it appears that women, mostly in customer service jobs, learn how to carry out their tasks by themselves and may feel that they should avoid disturbing their colleagues. They also have less access to knowledge transmission. While their jobs may seem less dangerous, they are not free of hazards, especially for WMSD, as documented in this study. It is difficult for women, in this context, to develop efficient strategies to protect themselves from later injuries. Our results underscore the importance of developing prevention programs, in particular introduction and safe integration programs, considering the jobs often held by women, such as jobs with customers. This illustrates the importance of a gendered perspective considering the exposure to different risk factors but also the temporal dimension.

\section{Acknowledgments}

The authors acknowledge the Institute of Gender and Health (Canadian Institutes of Health Research CIHR), the Fonds de recherche en Santé du Québec (FRSQ), the Ministry of Education of the Québec Province, the Québec Occupational Health and Safety Network (RRSSTQ) and the Institut de recherche Robert-Sauvé en santé et sécurité du travail (IRSST) for their financial support. The authors are all member of CIHR Team in Gender, Environment and Health. 


\section{References}

[1] R. Arcand, F. Labrèche, S. Stock, S., K. Messing and F. Tissot, Travail et santé, in ESS 1998, 2e éd. Institut de la statistique du Québec, Montréal, 2001, pp. 525-570.

[2] F.C. Breslin, and P. Smith, Age-Related Differences in Work Injuries: A Multivariate, Population-Based Study, American Journal of Industrial Medicine 48 (2005), 50-56.

[3] F.C. Breslin, D. Day, E. Tompa, E. Irvin, S. Bhattacharyya, J. Clarke, and A. Wang, Non-agricultural Work Injuries Among Youth. A systematic Review, American Journal of Preventive Medicine 21 (2007a) 151-162

[4] F.C. Breslin, J. Polzer, E. MacEachen, B. Morrongiello, B. and H. Shannon, Workplace injury or "part of the job"?: Towards a gendered understanding of injuries and complaints among young workers, Social Science and Medicine 64 (2007b), 782-793.

[5] F.C. Breslin, Educational Status and work Injury Among Young People, Canadian Journal of Public Health 99 (2008), 121-124.

[6] F.C. Breslin and J..D. Pole, Work Injury Risk Among Young People With Learning Disabilities and Attention-Deficit / Hyperactivity Disorder in Canada, American Journal of Public Health 99 (2009), 1423-1430.

[7] B. Calvet, J. Riel, V. Couture and K. Messing, Work organisation and gender among hospital cleaners in Quebec after the merger of "light" and "heavy" work classifications, Ergonomics, iFirst acticle (2011), 1-13.

[8] K. Chassaing, Vers une compréhension de la construction des gestuelles avec l'expérience : le cas des tôliers d'une entreprise automobile, PISTES 6, (2004).

[9] C. Chatigny, Les ressources de l'environnement : au cœur de la construction des savoirs professionnels en situation de travail et de la protection de la santé, PISTES 3 (2001).

[10]CSST, Portrait des jeunes travailleurs de 24 ans et moins Année 2008, Bibliothèque et Archives nationales du Québec, 2009.

[11]CSST, Prendre le temps de former et de superviser les jeunes et les nouveaux travailleurs, C'EST PAYANT! 2010.

[12] P. Duguay, P. Massicotte and P. Prud'homme, Lésions professionnelles indemnisées au Québec en 2000-2002. I - Profil statistique par activité économique, IRSST, Rapport R-547. Montréal, 2008.

[13] M. Gervais, P. Massicotte, and D. Champoux, Conditions de travail, de santé et de sécurité des travailleurs du Québec. IRSST, Rapport R-449, Montréal, 2006.

[14]C. Gaudart, C. Delgoulet, K. Chassaing, La fidélisation de nouveaux dans une entreprise du BTP : Approche ergonomique des enjeux et des déterminants, Activités 5 (2008).

[15]F. Guérin, A. Laville, F. Daniellou, J. Duraffourg, H. Rouilleault, Comprendre le travail pour le transformer : la pratique de l'ergonomie. ANACT, $4^{\text {th }}$ edition, Lyon (France), 2006
[16]M. Laberge, N. Vézina, B. Calvet, B. and E. Ledoux, Le PFAE. Quelles sont les implications pour la SST ?, Travail et santé 26 (2010), S7-13.

[17]M. Laberge, and E. Ledoux, Occupational Health and Safety Issues Affecting Young Workers: A Literature Review, Work 39 (2011), 215-232.

[18] M. Laberge, N. Vézina, B. Calvet, S. Lévesque and L. VézinaNadon, L'accueil et l'intégration sécuritaire et compétente des jeunes travailleurs dans les métiers peu spécialisés : une démarche collective, submitted.

[19]M. Laberge, Accueil et intégration sécuritaire et compétente en emploi des élèves inscrits à la formation menant à un métier semi-spécialisé du parcours de formation axée sur 1'emploi. Ph.D Dissertation, UQAM, Montréal, in press.

[20] J. Lave, E. Wenger, Situated Learning: Legitimate Peripheral Participation, Cambridge University Press, Cambridge, 1991.

[21] MELS, Programme de formation de l'école québécoise. Enseignement secondaire, $2^{\text {nd }}$ cycle. Formation préparatoire au travail et formation menant à l'exercice d'un métier semispécialisé, Les publications du Québec, 2008, chap. 1-5 \& 10.

[22] K. Messing, L. Punnett, M. Bond, K. Alexanderson, J. Pyle, S. Zahm, D. Wegman, S.R. Stock and S. de Grosbois, Be the fairest of them all: Challenges and recommendations for the treatment of gender in occupational health research, American Journal of Industrial Medicine, 43 (2003), 618-629.

[23] S. Ouellet and N. Vézina, Savoirs professionnels et prévention des TMS : réflexions conceptuelles et méthodologiques menant à leur identification et à la genèse de leur construction, PISTES, 10 (2008)

[24] S. Ouellet and N. Vézina, Savoirs professionnels et prévention des TMS: portrait de leur transmission durant la formation et perspectives d'intervention, PISTES, 11 (2009).

[25]Quebec Government, An Act respecting industrial accidents and occupational diseases, R.S.Q., chapter A-3.001, 2011

[26]C. Sabag-Vaillancourt and S.J. Mathieu, Les travailleuses québécoises et les lésions professionnelles. Où en sommesnous? Rapport CSST, Québec, 2006.

[27]M. St-Vincent, M. Lortie and C. Tellier, Évaluation d'un programme de formation à la manutention, in $\mathrm{M}$. Gagnon, $\mathrm{M}$. Lortie, and M. St-Vincent, Résumé de trois études sur les préposés aux malades dans un hôpital pour soins prolongés, chap. 2, IRSST, Rapport B-035, Montréal, 1989.

[28]M. St-Vincent, N. Vézina, M. Bellemare, D. Denis, E. Ledoux and D. Imbeau, L'intervention en ergonomie, sous la coordination de Lapierre, J, Éditions Multi Mondes, Québec, 2011.

[29]N. Vézina, La pratique de l'ergonomie face aux TMS : ouverture à l'interdisciplinarité, in : Abstract of SELF-ACE Conference, Montreal, 2001.

[30] WCB, Manitoba Workplace Injury- and Illness Statistics Report 2000-2006, Manitoba, 2008. 